\title{
Cholinergic Innervation of the Smooth Muscle Cells in the Choroid Coat of the Chick Eye and Its Development
}

\author{
Stephen D. Meriney a and Guillermo Pilar \\ The University of Connecticut, Department of Physiology and Neurobiology, Storrs, Connecticut 06268
}

The mechanical and pharmacological characteristics of the cholinergic activation of the smooth muscle in the choroidal coat of the chick eye have been assessed in tissues isolated from birds $1 \mathrm{~d}$ posthatching using histological, electrophysiological, and immunological techniques. The choroidal coat is innervated by a dense network of cholinergic nerves that make en passant synapses with smooth muscle. Thirty-hertz stimulation of these nerves initiates red blood cell (RBC) movement in the vessels of the choroidal coat, and this activation is blocked by muscarinic ACh receptor (AChR) antagonists. Force-transducer recordings of nerve-induced contractions of this tissue have a slow onset and relaxation time course similar to those of smooth muscle contractions. Furthermore, since nearly half the cholinergic neurons innervating the choroid die within a defined period during development, the onset and pharmacology of this innervation were studied during embryogenesis. With a neural cytoskeletal-like immunostain, we demonstrated that choroid axons are present in peripheral tissue by stage (St) 29. Extracellular electrical recordings made after choroid nerve stimulation allowed us to distinguish axon from muscle responses. These procedures permitted us to examine the time course of the innervation of the smooth muscle. However, to visualize the postsynaptic smooth muscle response, it was necessary to treat the isolated preparation with tetraethylammonium chloride (TEA). Accordingly, TEA-enhanced electrical smooth muscle responses to single-nerve stimuli could be recorded only after St 39 . Treatment of the nervemuscle preparation with prostigmine allowed the recording of TEA-enhanced electrical activity as early as St 36 (1 d after the beginning of the normal choroid neuron death period). This synaptic activation was completely blocked by atropine or quinuclidinyl benzylate (QNB), and was not affected by alpha bungarotoxin ( $\alpha \mathrm{BTX}$ ), indicating that, as in the posthatching tissue, neuromuscular transmission is mediated by muscarinic receptors. These results show that cho-

\footnotetext{
Received Jan. 27, 1987; revised June 8, 1987; accepted June 11, 1987.

We thank L. Landmesser, L. Dahm, and D. B. Gray for critical evaluation of the manuscript, M. J. Spring for artwork, and S. Putnam for her editorial assistance. This work was supported by NIH 10338, NSF-BNS 8410581 , and The University of Connecticut Research Foundation.

Correspondence should be addressed to Dr. Guillermo Pilar, The University of Connecticut, Department of Physiology and Neurobiology, 75 N. Eagleville Rd., Rm. 416 U-42, Storrs, CT 06268.

a Present address: Jerry Lewis Neuromuscular Research Center, UCLA School of Medicine, 700 Westwood Plaza, Los Angeles, CA 90024.
}

Copyright (C) 1987 Society for Neuroscience $0270-6474 / 87 / 123827-13 \$ 02.00 / 0$ linergic muscarinic activation of the choroidal coat can occur as early as St 36 , but that it is not as efficient as transmission later in embryogenesis.

The choroidal coat of the vertebrate eye is essentially a vascular rete that lies between the sclera and retina and encapsulates the vitreous body. Early studies of the peripheral distribution of efferent nerves from the parasympathetic chick ciliary ganglion described the projection of some of these nerves to the choroid coat (Marwitt et al., 1971), but a detailed study of this innervation has not been done. In this paper, a more complete description of the innervation and its development is presented. The determination of the time of onset and the pharmacology of transmission in this tissue during embryogenesis is important, because nearly half the neurons from the cholinergic population, which will eventually innervate this tissue, die during a defined developmental time period. It has been shown that the neurons in the ciliary population compete among themselves in the target region (the iris and ciliary body) (Pilar et al., 1980), and it has been assumed that the choroid population also engages in competition for survival. Since it is known that the survival of these neurons depends on the presence of the target (Landmesser and Pilar, 1974), a detailed description of the development of the cholinergic innervation of the choroidal coat is required for the interpretation of observations of neuronal death following $\mathrm{ACh}$ receptor (AChR) blockade (see Meriney el al., 1987).

There are other reasons that this study may be of general interest. The retina of birds is avascular, and Rochon-Duvigneaud (1943) suggested that the choriocapillaris (a part of the choroidal coat; see below) may be responsible for nourishing the outer layers of the retina. In addition, since the pigmented epithelial cells can transport ions at a rapid rate (Noell et al., 1965; Lasansky and de Fisch, 1966) and appear to be responsible for at least part of the transretinal potential, it is possible that the choroid may serve as a source and sink of ions involved in the epithelial transport processes. Furthermore, the pharmacological and contractile characteristics of the choroid are also of clinical interest, since cholinergic activation of this tissue may regulate blood flow and intraocular pressure.

In this work, we describe morphological characteristics of the cholinergic muscarinic innervation of this tissue at the lightand electron-microscopic levels, and the pharmacology of the choroid muscle's contractile response to choroid nerve stimulation in the posthatching chick. We describe also the organization of the choroid coat. These observations are extended to the study of the development of the cholinergic innervation of the choroid coat during embryogenesis, with emphasis on the 
period of normal cell death at stage (St) 34-40. We define the time of the onset of innervation, functional neuromuscular transmission, and appearance of AChRs on the postsynaptic muscle cells of the choroid.

\section{Materials and Methods}

White Leghorn chick embryos were incubated in a forced-draft incubator to the desired stage (Hamburger and Hamilton, 1951). Choroid tissue from chicks of embryonic and posthatch ages was dissected out intact with the sclera, retina, and pigment layers. The same region of the choroid was used for all experimental procedures. This region is defined by an isosceles triangle whose apex is the point at which the choroid nerves pierce the sclera, and whose base is the border of the ciliary body. One side is bounded by the ciliary nerves, and the other side is determined by the equal lengths of one side and the base, which create the isosceles triangle. A superfusion solution of Tyrode's was used with $134 \mathrm{~mm} \mathrm{NaCl}, 3 \mathrm{~mm} \mathrm{KCl}, 20 \mathrm{~mm} \mathrm{NaHCO}, 3 \mathrm{~mm} \mathrm{CaCl}, 1 \mathrm{~mm}$ $\mathrm{MgCl}_{2}$, and $12 \mathrm{~mm}$ glucose. Drugs were added to the superfusion solution and their effects recorded at the indicated intervals. $\mathrm{ACh}$, alpha bungarotoxin ( $\alpha \mathrm{BTX}), d$-tubocurarine chloride (dTC), and atropine sulfate were obtained from Sigma Chemical Co. (St. Louis, MO). Tetraethylammonium chloride (TEA) was obtained from J. T. Baker Chemical Co. (Phillipsburg, NJ). Prostigmine and quinuclidinyl benzylate (QNB) (generously provided by Dr. P. Sorter) were obtained from Roche (Nutley, NJ).

Electron microscopy. The tissue from 1-d-old chicks was fixed in $1.5 \%$ glutaraldehyde, $1.5 \%$ paraformaldehyde, and $1.5 \%$ acrolein in $0.1 \mathrm{M}$ cacodylate buffer (pH 7.3) for $5 \mathrm{hr}$. Specimens were postfixed in $2 \%$ osmium tetroxide for $1 \mathrm{hr}$ and dehydrated for embedding in Eponaraldite such that transverse thin sections could be cut on an ultramicrotome. Thick $(1 \mu \mathrm{m})$ sections were mounted on glass slides and stained with toluidine blue. Thin sections were mounted on \#200 mesh grids and sequentially stained with $2 \%$ uranyl acetate and $1.5 \%$ lead citrate for viewing with a Phillips 300 electron microscope. Photograph montage reconstructions of large areas $\left(200 \mu \mathrm{m}^{2}\right)$ of the choroid coat allowed the identification of all cell types and their organization in this tissue.

Neural cytoskeletal-like immunostaining of choroid axons. Wholemount preparations of choroidal tissue were separated from the sclera and retina and pinned to the bottom of a Sylgard-coated $35 \mathrm{~mm}$ tissue culture dish. The pigment layer adhered to the choroid in most young embryos (St 34-40), and was removed by gently rubbing with a cotton bud. These whole-mounts were dipped in dry-ice-cold acetone for 15 sec, washed several times, and incubated overnight in phosphate-buffered saline with $0.3 \%$ Triton X-100 (PBST). A mouse hybridoma supernatant (generously provided by $\mathrm{H}$. Tanaka and L. Landmesser; sce Yamamoto et al., 1986), specifically directed against an as-yet undefined neural cytoskeletal element, was incubated with the choroid tissue for $1 \mathrm{hr}$, followed by several changes in PBST and fixation with $4 \%$ paraformaldehyde. This antibody has been observed to stain the neurites of chick spinal cord motoneurons from their earliest outgrowth throughout development. This was determined by comparing its staining to that of a second monoclonal directed against a motoneuron-specific cell surface antigen (L. Landmesser, unpublished observations). In addition, this antibody stains neuritic outgrowth from cultured chick spinal motoneurons (L. Landmesser and L. Dahm, unpublished observations). The cytoskeletal antigen was visualized under a fluorescent microscope after incubation in goat anti-mouse tetramethylrhodamine isothiocyanate (TRITC) conjugate $(1: 50)$ for $45 \mathrm{~min}$ and mounting on glass slides; photographs were taken for permanent records.

Observations of blood flow in the choroid coat. To determine the response of the choroidal vessels at various embryonic ages to choroid nerve stimulation and ACh application, the ciliary ganglion was surgically removed, together with the postganglionic choroid nerves and a large piece of choroidal tissue, and placed in heparinized Tyrode's. The sclera, retina, and pigment were removed, and the choroidal coat was pinned to the bottom of a Sylgard-coated perfusion chamber. Red blood cells (RBCs) were observed in choroidal vessels under Hoffman-modulation contrast optics $(\times 200)$ in this isolated tissue "sheet." Following either $30 \mathrm{~Hz}$ choroid nerve stimulation or pressure application of $50 \mu \mathrm{l}$ drop $1 \mathrm{~mm}$ ACh solution, the number of vessels in the whole microscopic field in which a movement of RBCs occurred was noted and scored.

India ink-fill of choroid vasculature. To visualize the vascular bed in the choroid coat, hatchling chicks were anesthetized with methoxyflurane and heparinized saline was injected into the ventricle of the heart, followed by a $1 \mathrm{ml}$ injection of Carter's ink. Chicks were immediately decapitated and choroidal tissue was removed, isolated, mounted in glycerine as described for immunostaining, and observed with light microscopy. Photographs were taken for permanent records.

Mechanical responses recorded from choroid muscle fibers. To determine the pharmacology and contractile characteristics of nerve-induced choroid activation in the hatched chick, mechanical recordings of muscle tension were made in isolated choroid coat. Tension is generated in this tissue by activation of smooth muscle cells and is measured with a force-transducer. With these recordings, we are unable to determine whether the mechanical response results from vasoconstriction, vasodilation of the blood vessels, or contraction of the suspensory ligaments (see below). It is likely that the responses observed are a combination of more than one of these elements and the result of the geometry of the recording situation, which was manipulated to maximize the amplitude of the response. Since we are unable to determine from which part of the organ the contraction originated, we have avoided ascribing a functional role for the cholinergic activation, and only refer to a movement of blood cells.

The effects of dTC, $\alpha \mathrm{BTX}$, and atropine on the synaptic activation of the choroid muscle contractions were ascertained in preparations where the ciliary ganglion was surgically removed with the choroid nerves and a wedgelike piece of the choroid coat. The distal end of the choroid (near the ciliary body insertion into the sclera) was lifted free of the sclera on one side and of the retina on the other, and tied directly to the homemade strain gauge. The choroid nerves were stimulated at $20 \mathrm{~Hz}$ at their emergence from the ciliary ganglion, and contractions in the choroid coat were monitored on a chart recorder.

Surgical denervation of the choroid. To determine the contribution of the ciliary ganglion to the innervation of the choroidal coat, a surgical denervation was performed. Hatchling chicks were anesthetized with methoxyflurane, and a small incision was made between the eye and the opening of the auditory canal to gain access to the posterior portions of the optic cup. The eye was retracted and the ciliary ganglion was located by blunt dissection. All postganglionic (ciliary and choroid) nerves leaving the ganglion were cut with iridectomy scissors and, in most cases, the ganglion was also completely removed. The success of the surgery was evaluated 2,3 , or 4 d later, when the choroidal coat was removed for immunohistochemistry. We used only those birds that had no pupillary response in the operated eye, no connection between the ciliary ganglion and the sclera, and a vascularized choroidal coat that appeared healthy.

Extracellular recording of TEA-enhanced electrical activity. For extracellular recording of electrical activity in the choroid, the ciliary ganglion was dissected intact with the choroid nerves and a piece of the choroidal coat. The sclera, pigment, and retinal layers were gently removed from the choroid to allow a recording suction electrode access to the tissue. Suprathreshold single stimuli were delivered via a suction electrode to the postganglionic choroid nerves, and electrical activity recordings were stored via a digitizer (PCM-1; Medical System, Greenville, NY) and a Sony Beta Hi-Fi Stereo Video Cassette Recorder (SLHF500). Prostigmine $\left(10^{-6} \mathrm{gm} / \mathrm{ml}\right)$ and/or TEA $(5 \mathrm{~mm})$ were added to the Tyrode's solution superfusing the preparation, and activity was recorded at regular intervals, depending on the age of the chick. Embryonic preparations were stimulated once per minute to reduce fatigue of embryonic synapses. The ability of atropine $(2 \mu \mathrm{M})$, QNB $(10 \mathrm{nM})$, and $\alpha \operatorname{BTX}(7.5 \mu \mathrm{g} / \mathrm{ml})$ to modify the activity recorded in the choroid coat was also evaluated.

Extracellular recording of isolated control choroid nerves was used as a comparison for the responses to TEA and prostigmine recorded in intact peripheral choroid tissue. To evaluate the frequency response of activity recorded in either the choroid tissue or choroid nerves themselves, the tissues were stimulated at $20 \mathrm{~Hz}$, and responses were continuously recorded for 15-25 sec. At regular intervals following the onset of the repetitive stimulation, the square of the area under the extracellular waveform was measured on a digital oscilloscope (7854 Textronix; Beavertown, $O R$ ) and plotted as a function of time.

\section{Results}

Cholinergic innervation of the mature organ

Choroid nerves leaving the ciliary ganglion pierce the sclera at 5-7 locations near the exit of the optic nerve and radiate over the choroidal coat (Fig. 1). Major choroidal vessels diverge from 


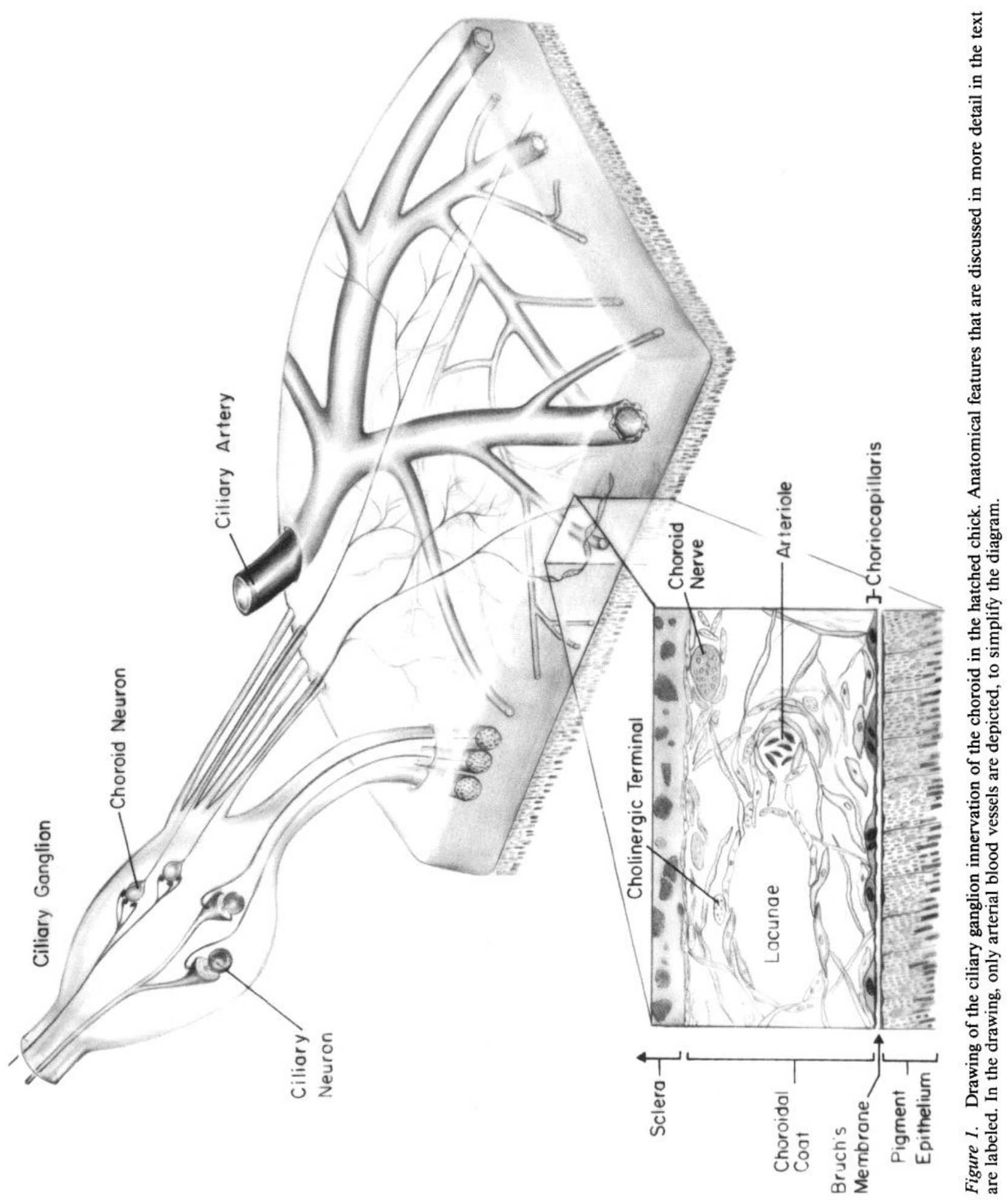




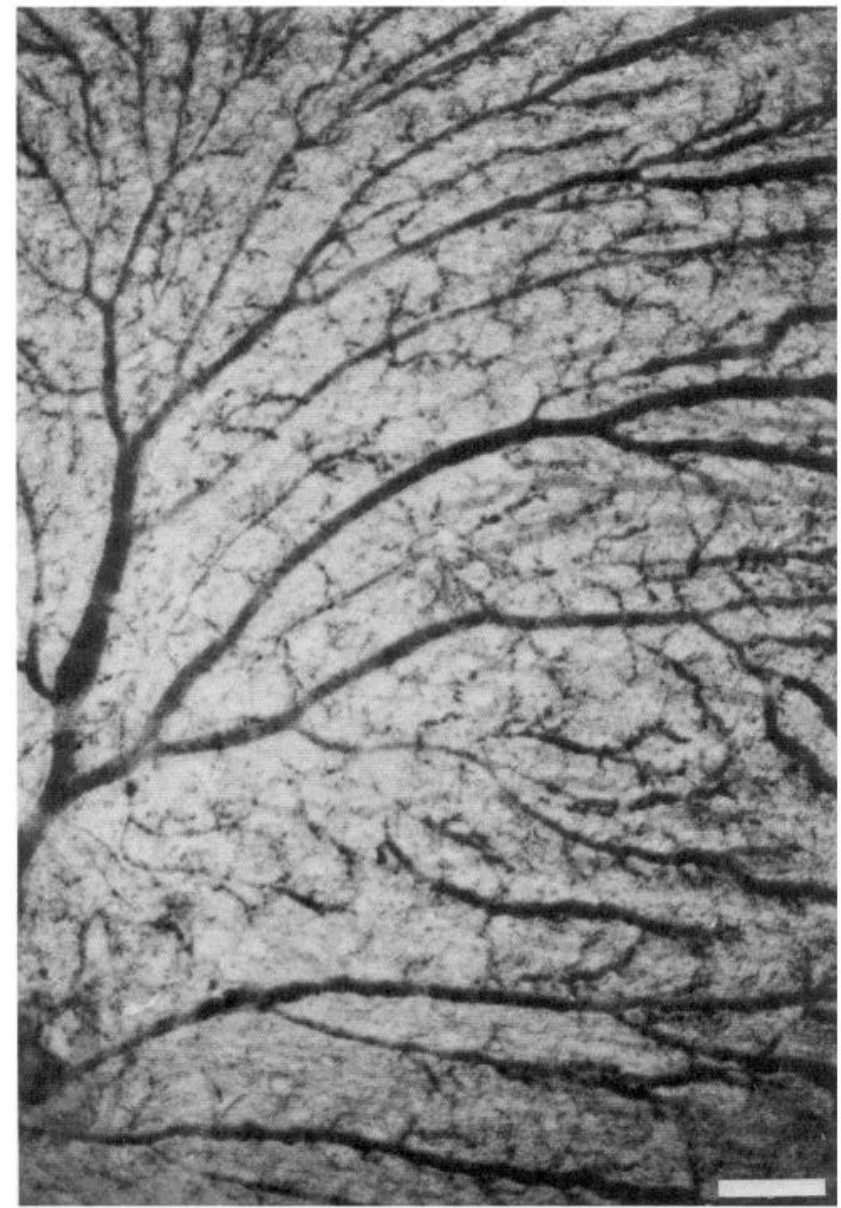

Figure 2. India ink-fill of the choroidal vasculature. The dense vascular bed that permeates this tissue is clearly delineated. Calibration, $15 \mu \mathrm{m}$.

the entrance into the sclera to create a dense vascular bed that breaks up into a capillary network between arterioles and venules (see Fig. 2). Most of the choroidal volume is made of lacunae, which consist of large endothelial-lined fluid reservoirs, connected to the blood vessels. We have not determined whether there are lacunae between capillaries or large vessels, but we observed lacunae connected to arterioles by narrow openings formed by endothelial cells wrapped by innervated smooth muscle cells. This heavily vascularized choroidal tissue forms a complete cuplike structure over the entire back of the eye, surrounding the vitreous humour.

Neuronal cytoskeletal immunoreactivity and changes following denervation. In the hatched chick, the density of innervation was observed following indirect immunofluorescence staining with a monoclonal antibody to an undefined neural cytoskeletal element. Figure 3, $A, B$, demonstrates the dense network of nerve fibers that runs between the large arterioles and venules (V) but does not heavily innervate them. The densest innervation appears around small vessels (v) in the choroidal coat (right, Fig. 3B).

Since both sympathetic and parasympathetic nerves innervate the choroid, the parasympathetic ciliary ganglion was surgically removed to determine the contribution of cholinergic nerves to the innervation observed by immunostaining (Fig. $4 A$ ). Two days after parasympathetic nerve denervation, the density of staining decreased dramatically such that only a few nerves remained (not shown). The possibility that a few sensory fibers had been surgically cut cannot be excluded. However, the degree to which sensory fibers innervate the choroid is unknown. This low density of innervation persisted for $4 \mathrm{~d}$ after parasympathetic denervation (Fig. $4 B$ ), presumably owing to the presence of a small number of sensory and/or sympathetic fibers. Kirby et al. (1978) have described the presence of a scarce adrenergic innervation of the choroid, which is in agreement with our conclusion that the vast majority of the immunoreactive nerves observed in the choroid coat clearly originate from the ciliary ganglion.

Ultrastructural observations of the innervation of the choroid. The tissue organization of the choroidal coat can be seen in the transverse $1 \mu \mathrm{m}$ section shown in Figure 5. At the bottom of this light photomicrograph are the outer layers of the retina (R). The pigment epithelium layer can be seen running between the photoreceptor cells of the retina and Bruch's membrane (b). The layer of the choroid coat closest to the retina is the choriocapillaris (c), which is followed by the larger vessel layers containing RBCs (v). The walls of the large vessels have ridgelike outcroppings that sometimes connect adjacent vessels and presumably serve some suspensory function, as suggested by Rochon-Duvigneaud (1943). The intravascular "suspensory" processes are composed of smooth muscle cells embedded in a collagen matrix. Choroid nerve branches (n) filled with myelinated axons usually run near the scleral edge of the choroid and subsequently branch into muscle nerves. Muscle nerve branches are unmyelinated and many axon profiles contain dense accumulations of small, clear vesicles (not shown). Within the choroidal coat, terminal axon branches run in groups and are usually bound together by Schwann cell processes that at least partially surround each fiber. At apparent "transmission" sites, vesicles fill varicose axons (Fig. $6 A, B, \mathrm{~V}$ ), which occasionally appose muscle membranes. There is no thickening or other apparent synaptic specialization of the nerve or muscle membranes. This en passant type of innervation is often seen in smooth muscle tissue, such as the vas deferens (Merrillees, 1968) and urinary bladder (Tachibana et al., 1985).

There were 2 different stages represented among the differentiated smooth muscle cells in the choroid coat at hatching. A layer of differentiated arteriole smooth muscle cells was easily identified; it lay immediately adjacent to the endothelial wall of the vessel and did not appear to receive innervation (not shown). We assume that the activation of this muscle is mediated by blood-borne chemical factors. The smooth muscle found in the outer layers of the arterial walls and in the suspensory ligaments was much less differentiated at hatching. Electron-microscopic montages of large areas of the choroid coat were made to ease identification of cell types in this tissue. Elongated smooth muscle cells were easily observed in these montage reconstructions and allowed the characterization of the partially undifferentiated smooth muscle cells, since most of the contractile filaments were restricted to the elongated tips of the cells (Fig. $6 \mathrm{~A}, \mathrm{f}$ ). In regions surrounding the cell nucleus, a bulging of the cell was observed, and the cytoplasm contained a very active Golgi apparatus (Fig. 6A, g) and endoplasmic reticulum. As described above, these smooth muscle cells received a dense innervation. All of these features are displayed from different cells in Figure $6 A$, as montage reconstruction of an entire smooth muscle cell is cumbersome to present in a figure.

Choroid muscle pharmacology and contractile responses. Since 

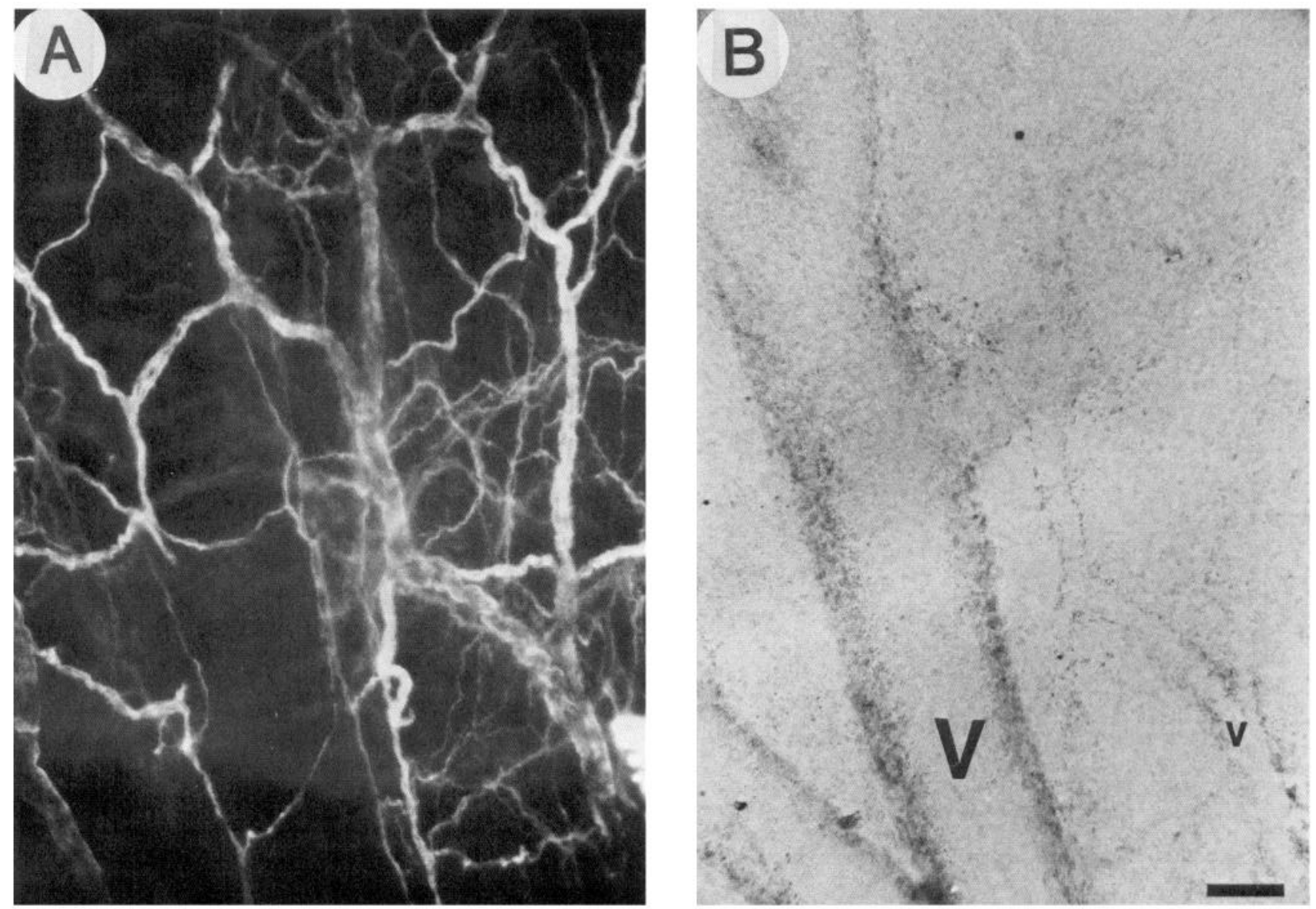

Figure 3. Undefined neuronal cytoskeletal immunoreactivity (see Materials and Methods) in the hatchling chick. Fluorescence $(A)$ and phasecontrast $(B)$ micrographs of the same field reveal that the density of innervation is highest around smaller vessels $(v)$, as large ones $(V)$ are wrapped by nerve bundles only. Calibration, $15 \mu \mathrm{m}$.

the cholinergic innervation of the choroidal coat is thought to mediate vasodilation in the mammal, a change in blood flow following parasympathetic nerve stimulation would be expected. Accordingly, $30 \mathrm{~Hz}$ choroid nerve stimulation conspicuously moved blood in the vessels of the isolated choroid tissue (discussed in more detail below). Therefore, to measure the contractile response of smooth muscles that may be associated with this blood movement, a sensitive force-transducer was used to record contractions in the hatched chick. No responses to singlenerve stimuli were obtained, and noticeable contractions of the choroid coat were present only after 3 or more stimuli (at 50 $\mathrm{Hz}$ ) were delivered to the postganglionic choroid nerves (Fig. $7 A$ ). Contractions of the choroid coat had a slow onset and time course and were frequency-dependent (Fig. 7B), with an optimal frequency of stimulation of between 30 and $50 \mathrm{~Hz}$ for maximal force generation.

In the hatched chick, the choroid neuromuscular junction is blocked by atropine (Fig. 8A, c) and is not affected by dTC (Fig. $8 A$, b), or even by high doses $(15 \mu \mathrm{g} / \mathrm{ml}$ ) of $\alpha$ BTX (Fig. $8 B$, b). In Figure $8, A$, a and $B$, a, the control contractions elicited by $30 \mathrm{~Hz}$ stimulation applied to the choroid nerves are shown. These results indicate that this junction is muscarinic. However, the use of strain-gauge measurements of muscular contractions to characterize this neuromuscular junction during development is difficult. Our transducer was not sensitive enough to record any force generated by embryonic choroid muscle. In addition, developing nerve terminals would not be expected to be able to follow the frequency stimulation required to generate force in the choroid, since immature nerve terminals are known to fatigue very rapidly (see Fig. 11).

\section{Development of cholinergic choroid innervation}

TEA-enhanced electrical activity in embryonic choroid muscle. To expose the embryonic choroid neuromuscular transmission, we recorded extracellular electrical activity in the choroid tissue following a single suprathreshold nerve stimulus. At all embryonic ages examined (St 35-hatching), extracellular action potentials were recorded with a $10 \mathrm{msec}$ latency in almost all areas of the choroid target tissue (Fig. 9A). Since this activity was not affected by either muscarinic or nicotinic $\mathrm{AChR}$ antagonists, it appears to have been due entirely to presynaptic nerve action potentials. The inability to record postsynaptic muscle activity extracellularly is not surprising, since smooth muscle often responds to nerve stimulation with subthreshold slow, graded potentials that do not usually generate action potentials (Axelsson, 1970). These slow, graded potentials would not have been recorded by our extracellular electrode.

To detect electrical activity in the choroid smooth muscle, we attempted to induce action potentials in this normally "silent" tissue. Since TEA is known to block the rectifying $\mathrm{K}^{+}$ current in many tissues (Armstrong, 1966), it has been used to depolarize and induce "spiking" in some smooth muscles 

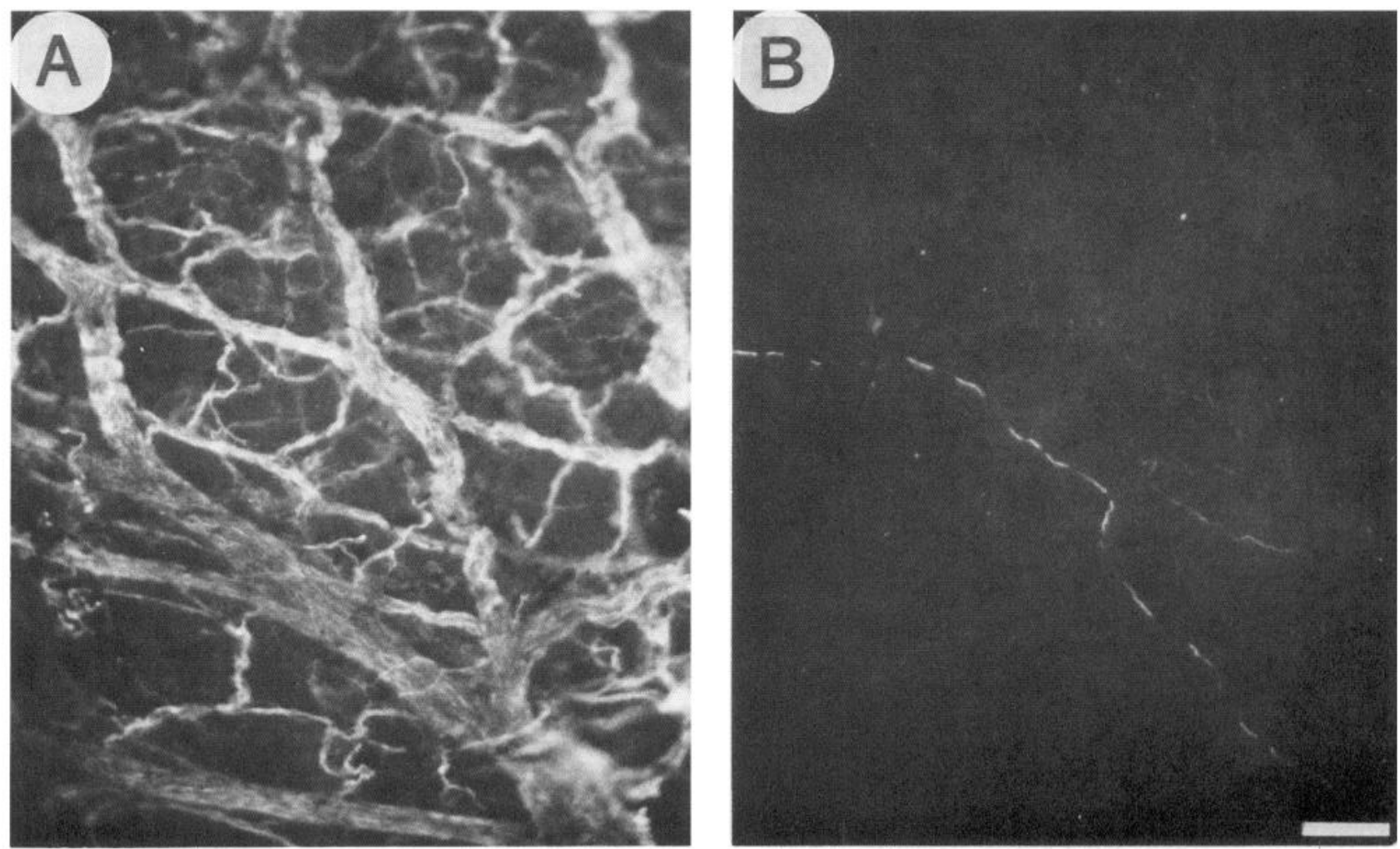

Figure 4. Immunostain of nerve fibers in a 4-d-posthatch control chick choroid $(A)$, and of nerve fibers denervated $4 \mathrm{~d}$ after surgical section of all the choroid nerves $(B)$. The dramatic decrease in staining indicates that most of the fibers observed with this antibody in $A$ stain nerves emanating from the ciliary ganglion. Calibration, $15 \mu \mathrm{m}$.

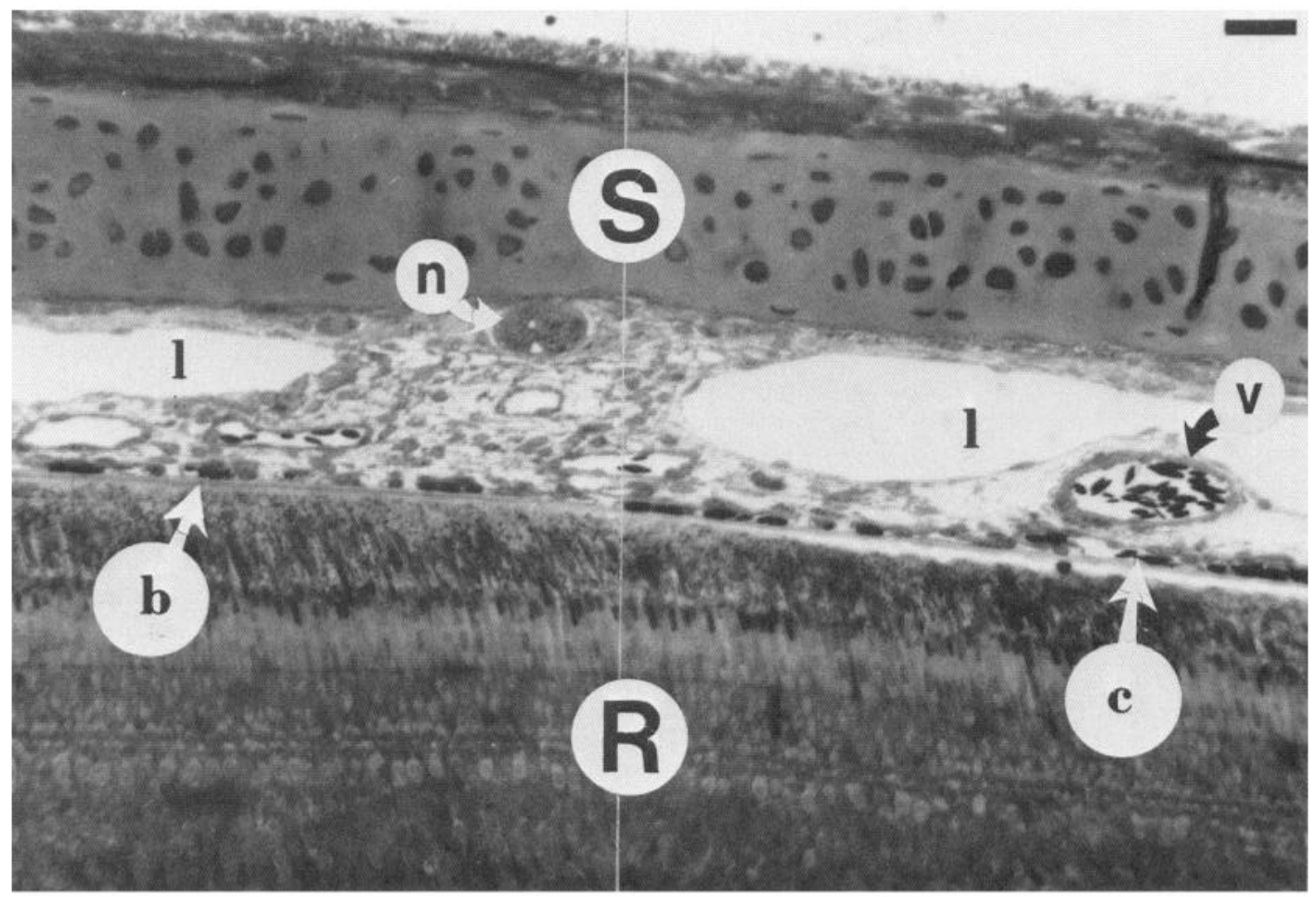

Figure 5. A $1 \mu \mathrm{m}$ section of the choroid and surrounding tissue. The choroid is sandwiched between the sclera $(S)$ and the retina $(R)$. Several vessels filled with RBCs can be seen $(v)$, as can a large choroid nerve bundle $(n)$ between 2 lacunae $(l)$. $b$, Bruch's membrane, $c$, choriocapillaris. Calibration, $20 \mu \mathrm{m}$. 

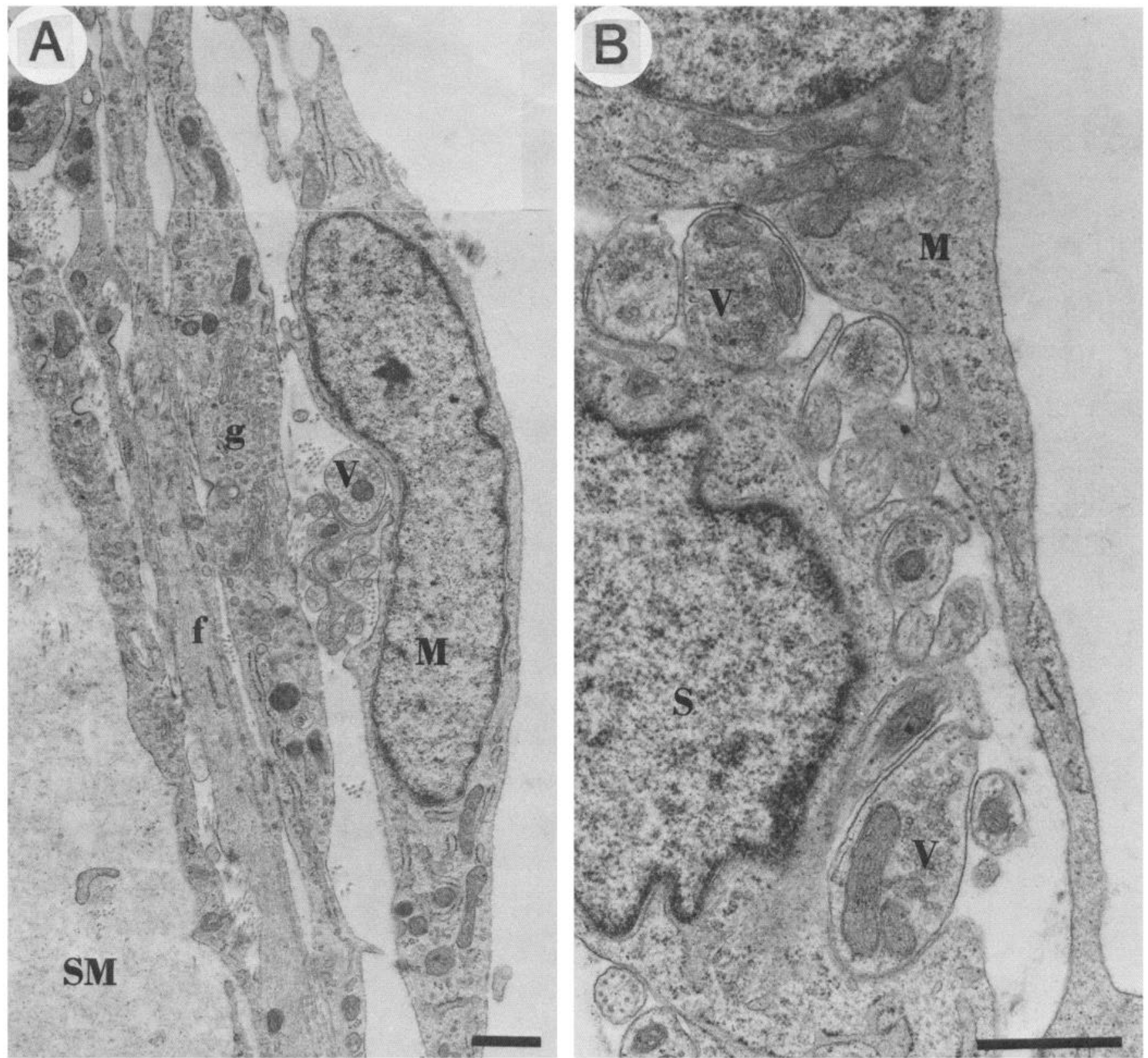

Figure 6. Electron micrographs of presumptive cholinergic endings in the choroid coat. Clear vesicles fill varicose synaptic endings $(V)$, which occasionally closely appose smooth muscle fibers $(M)$. $A$, A group of varicose axons runs between several smooth muscle fibers near the scleral edge of the choroid (SM, scleral matrix). These smooth muscle cells have a very active Golgi apparatus $(g)$ near nuclear regions, and contractile filaments $(f)$ in distal tips of the cell. $B$, Higher magnification of a different region of the choroid where several varicose axons $(V)$, partially surrounded by a Schwann cell $(S)$, run near a smooth muscle cell $(M)$. Calibration, $1 \mu \mathrm{m}$.

(Droogmans et al., 1977). Interestingly, TEA has a unique influence on smooth muscle: it blocks $\mathrm{K}^{+}$channels following extracellular exposure (Holman and Neild, 1979), whereas it has been shown to be effective in axons only when applied intracellularly (Armstrong, 1966). In the chick choroidal coat, superfusion with $5 \mathrm{~mm}$ TEA enhanced extracellularly recorded electrical activity in response to nerve stimulation such that a new, longer-latency compound action potential was recorded in the choroid tissue (Fig. 9B, arrow). This effect occurred 3-5 min after the onset of TEA superfusion and disappeared 3-5 min later (Fig. 9C). This transient appearance of detectable activity is presumably due to the time course of TEA-induced depolarization in the smooth muscle. As the membrane potential of the smooth muscle approaches threshold, single-nerve-induced postsynaptic depolarizations are enough to drive the muscle to fire an action potential. However, this drive is presumably lost as the TEA further depolarizes the tissue. Therefore, the TEAenhanced electrical activity was probably not a result of changes in the activity of muscle nerves, and was most likely the result of action potentials generated in postsynaptic muscle cells.

The pharmacology of the TEA-enhanced activity was investigated to determine if this muscle response was mediated via muscarinic synaptic activation. At all ages, atropine $(2 \mu \mathrm{M})$ or QNB (10 nM) completely blocked the longer-latency TEA-enhanced activity without affecting the shorter-latency nerve activity (Fig. 10, $A$ and $C$ are controls, while Fig. 10, $B$ and $D$ are 
A
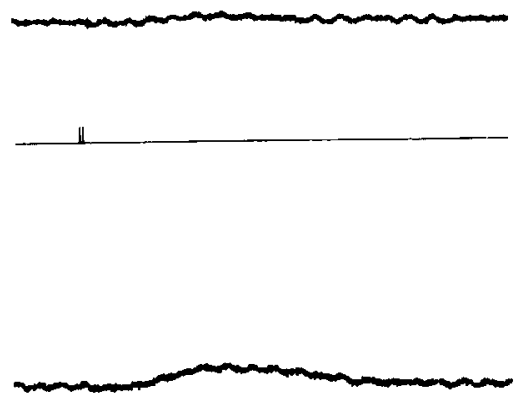

II

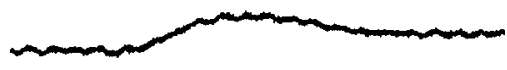

14
B

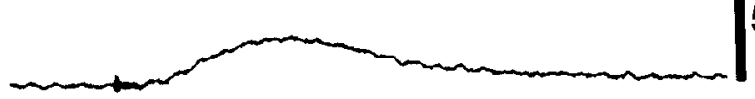

$\longleftrightarrow\lfloor\downarrow \downarrow \downarrow \downarrow \mid$

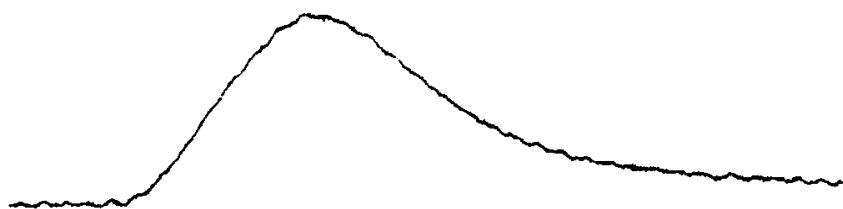

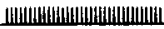

Figure 7. Choroid muscle contractions of the hatched chick in response to postganglionic choroid nerve electrical stimulation. $A$, Single (not shown) or double pulses applied to the choroid nerves do not clicit a mechanical response (upper trace). $\Lambda$ slow, protracted response is seen after 3 (middle traces) or 4 (lower traces) pulses. $B$, Choroid muscle contractions depend on frequency of stimulation. Upper trace, $10 \mathrm{~Hz}$; middle trace, $33 \mathrm{~Hz}$; lower trace, $50 \mathrm{~Hz}$.

A
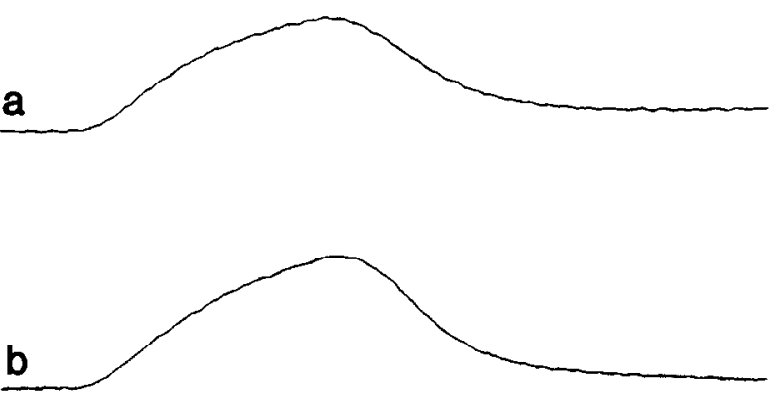

C

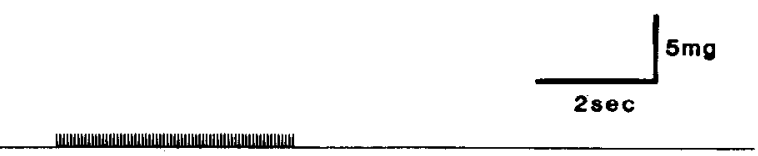

B
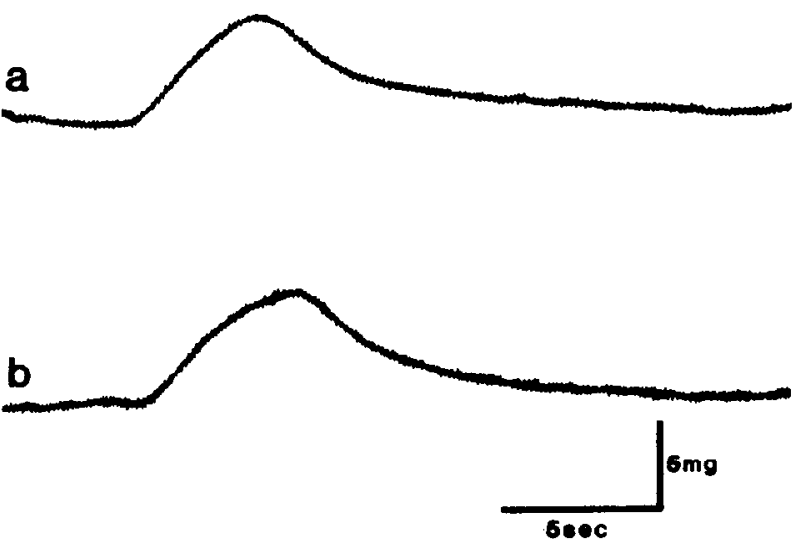

6eec

Figure 8. A, Effect of dTC and atropine on choroid muscle contractions elicited by postganglionic nerve stimulation ( $33 \mathrm{~Hz}$ ). $a$, Control tetanic contraction. $b, \mathrm{dTC}, 1 \mu \mathrm{M}$, does not influence the tetanic contraction. $c$, Atropine, $1.5 \mu \mathrm{M}$, completely blocks the generation of force in the choroid muscle after choroid nerve stimulation. $B$, Effect of $\alpha \mathrm{BTX}$ on choroid muscle contrations elicited by choroid nerve stimulation (33 Hz). $a$, Control tetanic contraction. $b, \alpha \mathrm{BTX}, 75 \mu \mathrm{g} / \mathrm{ml}$, added to the superfusion solution does not influence the tetanic contraction. 

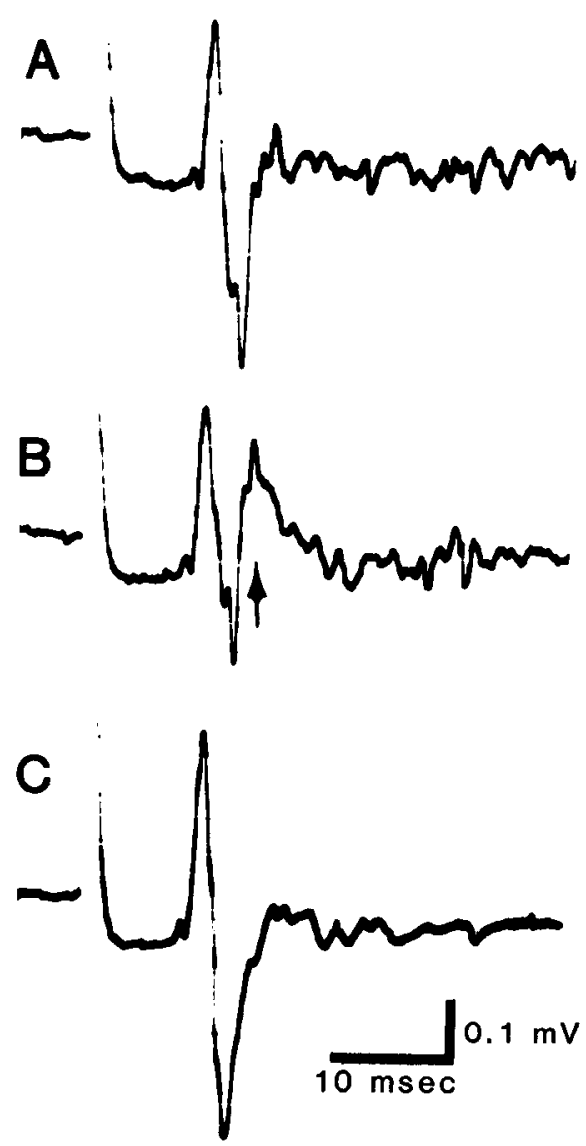

Figure 9. Extracellular recording of electrical activity in the choroid coat following single-shock stimulation of the choroid nerves ( $\mathrm{St} \mathrm{44).}$ $A$, Control. $B$, TEA, $5 \mathrm{~mm}$, enhances muscular activity such that it can be recorded extracellularly. $C$, Wash. In this figure and in Figures 10, 12 , and 13, the arrow indicates the TEA-elicited response.

responses after TEA application). In addition, $\alpha \mathrm{BTX}(7.5 \mu \mathrm{g} /$ $\mathrm{ml})$ was unable to affect the nerve- or TEA-enhanced activity (Fig. 10, arrow) (Fig. 10E, control; Fig. 10F, after TEA). These results indicate that the TEA-enhanced activity is synaptic, and that this choroid neuromuscular synapse is muscarinic throughout embryonic development. Pretreatment of the preparation with prostigmine increased the amplitude of the synaptic TEAenhanced electrical activity - further proof that this activity is cholinergic (discussed below).

Since TEA may be influencing axons as well as muscle electrical activity, extracellularly recorded compound action potentials from isolated choroid nerves were monitored after perfusion with TEA (not shown). After 6 min of TEA perfusion, no changes in the size and only small changes in the shape of nerve action potentials were noticed. If the TFA perfusion was continued for $30 \mathrm{~min}$, however, a broadening of the nerve action potential became apparent. This long-term effect of TEA on choroid nerve action potentials is not likely to have contributed to the enhanced activity recorded in the intact choroid tissue, since the long-latency muscle electrical activity recorded always appears 3-5 min after the onset of TEA perfusion and, in fact, disappears.

The frequency response of both nerve- and TEA-enhanced activity to $20 \mathrm{~Hz}$ nerve stimulation was examined between $\mathrm{St}$ 42 and hatching (Fig. 11). The responses from both isolated choroid nerves (Fig. 11, open circles) and muscle nerves (closed circles) recorded within peripheral choroid tissue decreased slowly and at a similar rate. In contrast, TEA-enhanced activity decreased very rapidly $(2 \mathrm{sec})$ during $20 \mathrm{~Hz}$ ncrve stimulation (see Fig. 11, triangles). This is a further indication that this electrical activity is postsynaptic, since embryonic synaptic transmission is known to fail during high-frequency stimulation. This failure of synaptic transmission is similar to that seen in embryonic iris junctions (Pilar et al., 1981) and developing frog neuromuscular junctions (Letinsky, 1974).

To determine the effective onset of transmission in this tissue (sufficient to activate a postsynaptic response), the effects of TEA on extracellular potentials recorded in the choroid were examined between St 35 and hatching. In Figure 12, it can be seen that TEA has no effect on eliciting a response at St 36; Figure $12 \mathrm{~A}$ is the control response, Figure $12 \mathrm{~B}$ is after TEA application, and Figure $12 C$ is 10 min after TEA. The earliest developmental stage at which TEA was able to enhance electrical activity (arrow) was St 39 (Fig. 12, D-F). To determine whether the de-
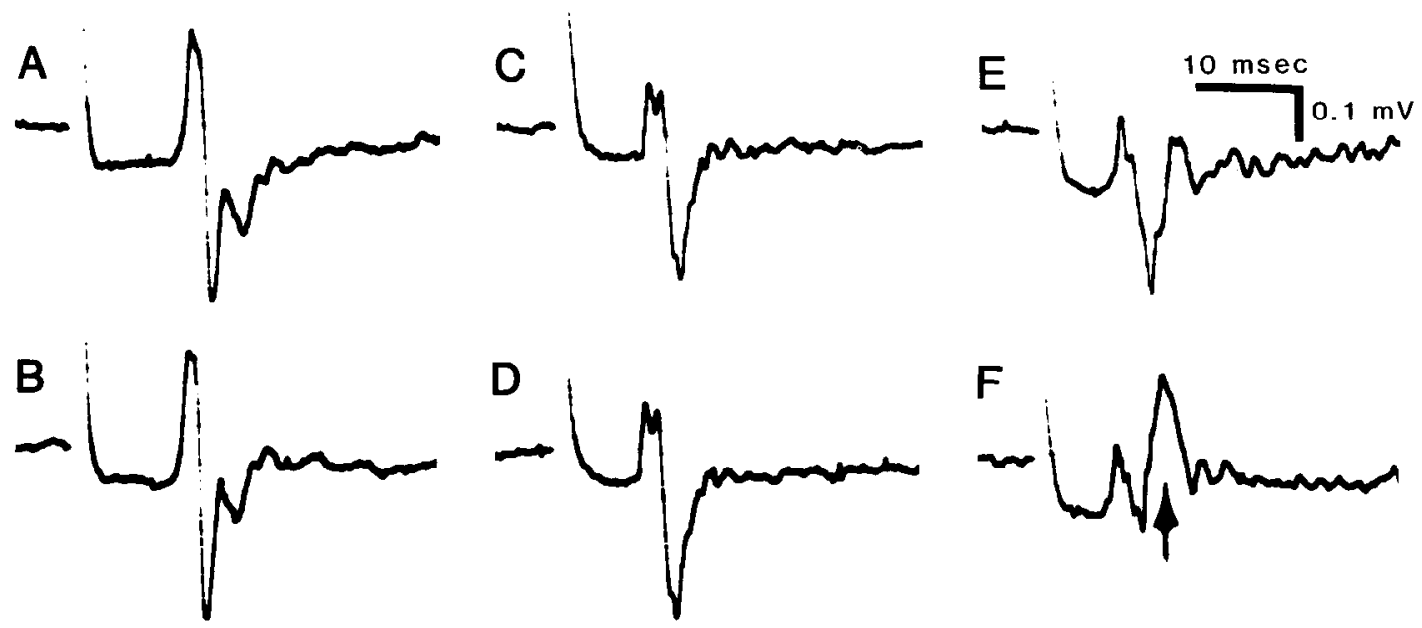

Figure 10. Pharmacology of the TEA-enhanced activity. All recordings from St 40. A, Control. B, Atropine, $2 \mu \mathrm{M}$, added to the superfusate completely blocks a response to $5 \mathrm{mM}$ TEA. In another preparation $(C), 10 \mathrm{nM}$ QNB also completely blocks the response to 5 mM TEA $(D)$. However, the electrical response to TEA is not blocked by the nicotinic AChR blocker $\alpha \mathrm{BTX}$. $E$, Control. $F, \alpha \mathrm{BTX}, 7.5 \mu \mathrm{g} / \mathrm{ml},+\mathrm{TEA}, 5 \mathrm{mM}$. 


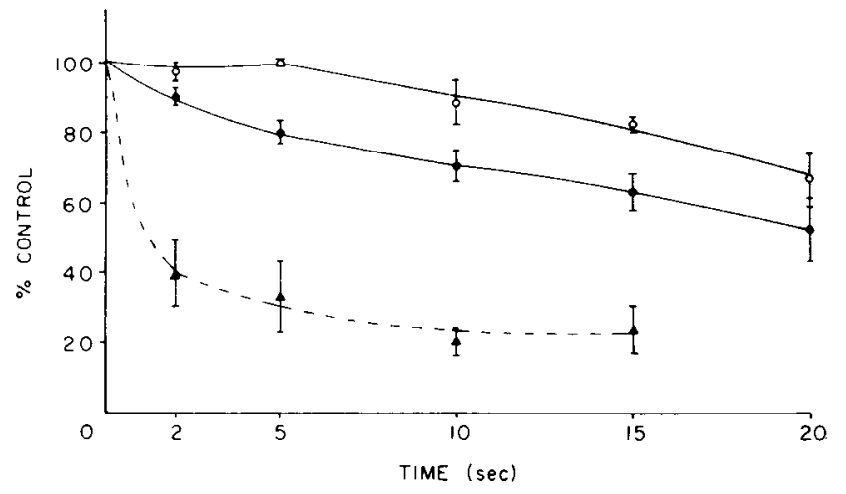

Figure 11. Frequency response of nerve (solid lines) and TEA-enhanced (dashed line) extracellularly recorded electrical activity (St 42). Choroid nerve stimulation $(20 \mathrm{~Hz})$ begins to slowly fatigue the compound action potential recorded in isolated choroid nerves $(O)$ after 5 sec. The activity recorded extracellularly in muscle nerves of the choroid coat (๑) shows an early decline, probably due to terminal axon branch block at this high frequency, but the fatigue levels off to parallel that observed in isolated choroid nerves. The TEA-enhanced activity recorded in the choroid coat $(\boldsymbol{\Lambda})$ fatigues very rapidly during a $20 \mathrm{~Hz}$ choroid nerve stimulation. Vertical lines, mean \pm SEM.

velopmental appearance of this TEA enhancement (St 39) was at the earliest embryonic age at which nerve stimulation could induce muscle activity, cholinergic transmission was facilitated by prior superfusion with prostigmine. TEA was able to enhance the electrical activity in prostigmine-treated tissues as early as St 36 (Fig. 13, A-C) and increased the size of TEA responses after St 39 (Fig. 13, D-F), which provides evidence for some transmission as early as St 36 . These records were compared to previous recordings made in the absence of prostigmine (not
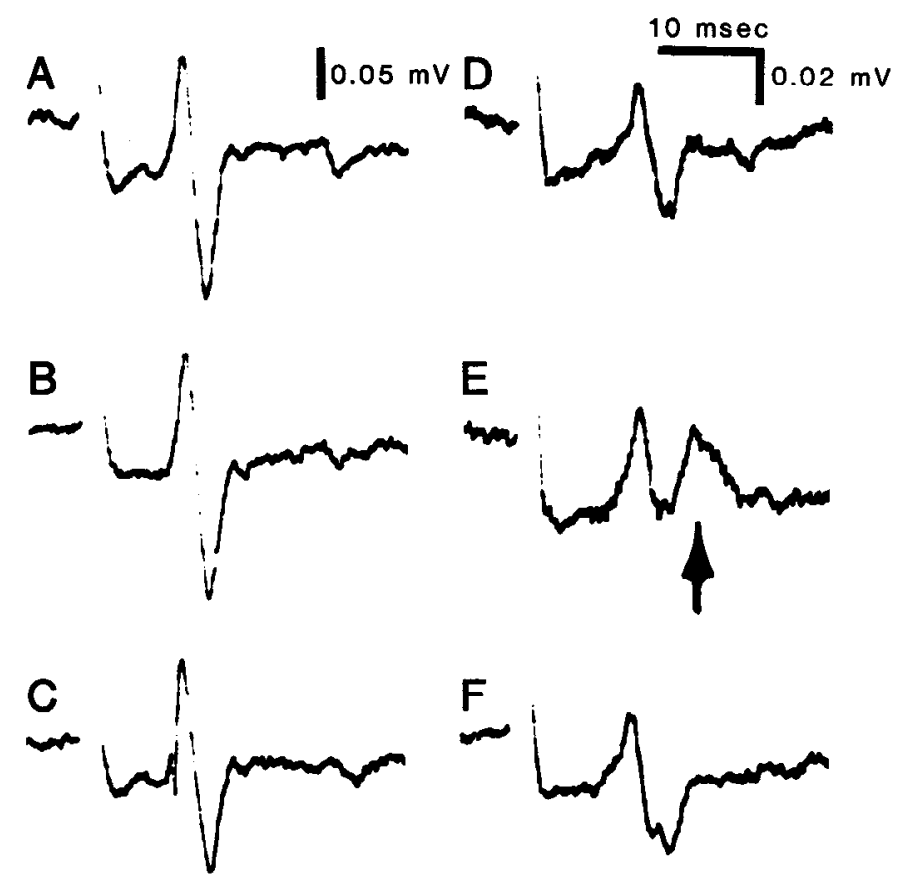

Figure 12. The developmental appearance of TEA-enhanced electrical activity. At St $36(A-C)$, there is no response to TEA. $A$, Control. $B$, TEA, 5 mM. $C$, Wash. The earliest developmental stage at which TEA enhances extracellularly recorded electrical activity is St $39(D-F) . D$, Control. E, TEA, 5 mm. $F$, Wash.

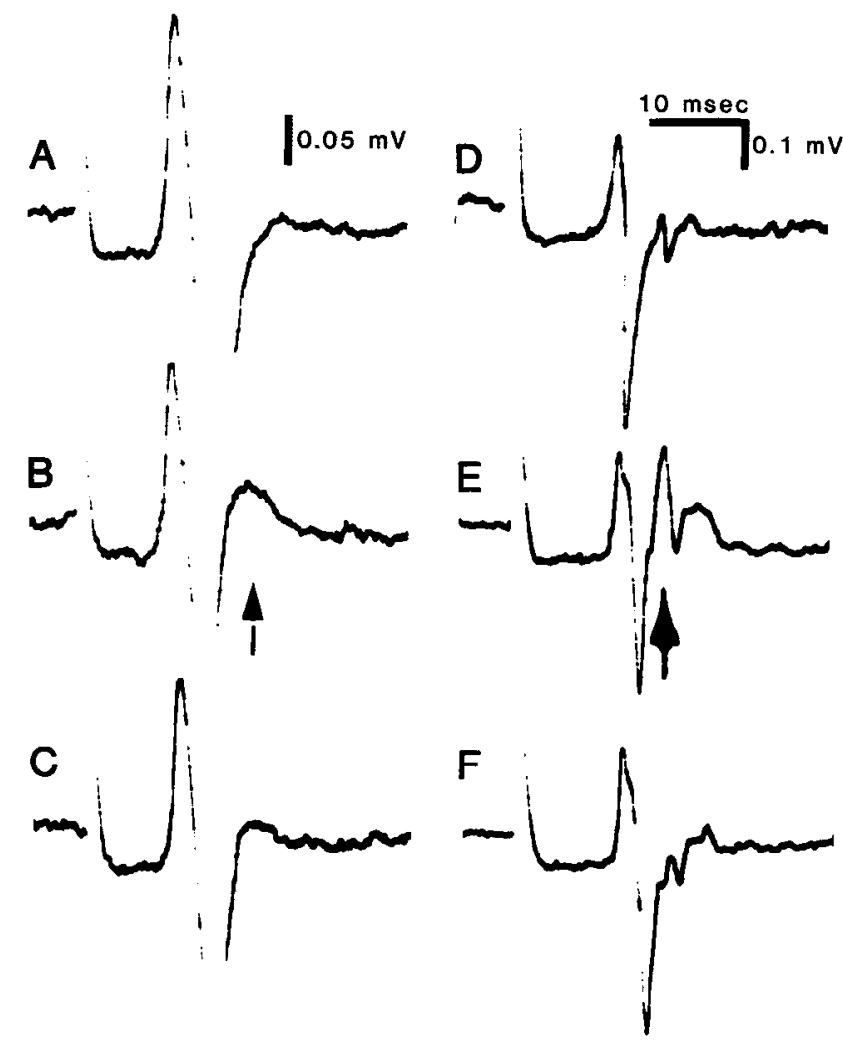

Figure 13. Prostigmine enhancement of TEA-enhanced electrical activity. A $30 \mathrm{~min}$ superfusion of prostigmine $\left(10^{6} \mathrm{gm} / \mathrm{ml}\right)$ allows the recording of a TEA-enhanced response as early as St $36(A-C)$. $A$, Control after prostigmine. $B$, TEA, $5 \mathrm{~mm}$, enhances activity such that a small response is observed after the nerve action potential. $C$, Wash. In addition, prostigmine enlarges the response at older embryonic ages $(D-F$, St 39). $D$, Control after prostigmine. $E$, TEA, $5 \mathrm{~mm}$, produces a large muscle response. $F$, Wash.

shown), which served as controls. This enhancement of the TEA electrical activity by prostigmine is further proof that these responses are cholinergic and postsynaptic. The prostigmine treatment required at these early embryonic ages may be necessary because the amount of $\mathrm{ACh}$ released from terminal varicosities might not yet be sufficient, or the distance over which the transmitter must diffuse is longer than it is later in development (see first paragraph of Discussion in Meriney et al., 1987).

Developmental appearance of cytoskeletal immunoreactivity. Developing choroid nerves reached the peripheral target area long before we were able to record choroid neuromuscular transmission (St 36). By St 29, neural cytoskeletal immunoreactivity demonstrated the growth of choroid axons into the periphery (Fig. 14A). By St 33, these axons began to ramify and traverse most of the choroidal coat (Fig. 14B). However, a dense network of nerves did not begin to form until St 38 (Fig. 14C). As the chick matured, the network of nerves became very thick, and denscly covercd the choroidal tissuc (Fig. 14D). Thesc obscrvations indicate that choroidal nerves are present in the periphery before the onset of transmission, and gradually ramify to densely innervate the choroidal muscle, presumably at the time that electrical recordings of the TEA-enhanced response are possible.

Observations of blood flow following ACh or nerve stimulation. To determine when the choroid could respond to ACh appli- 

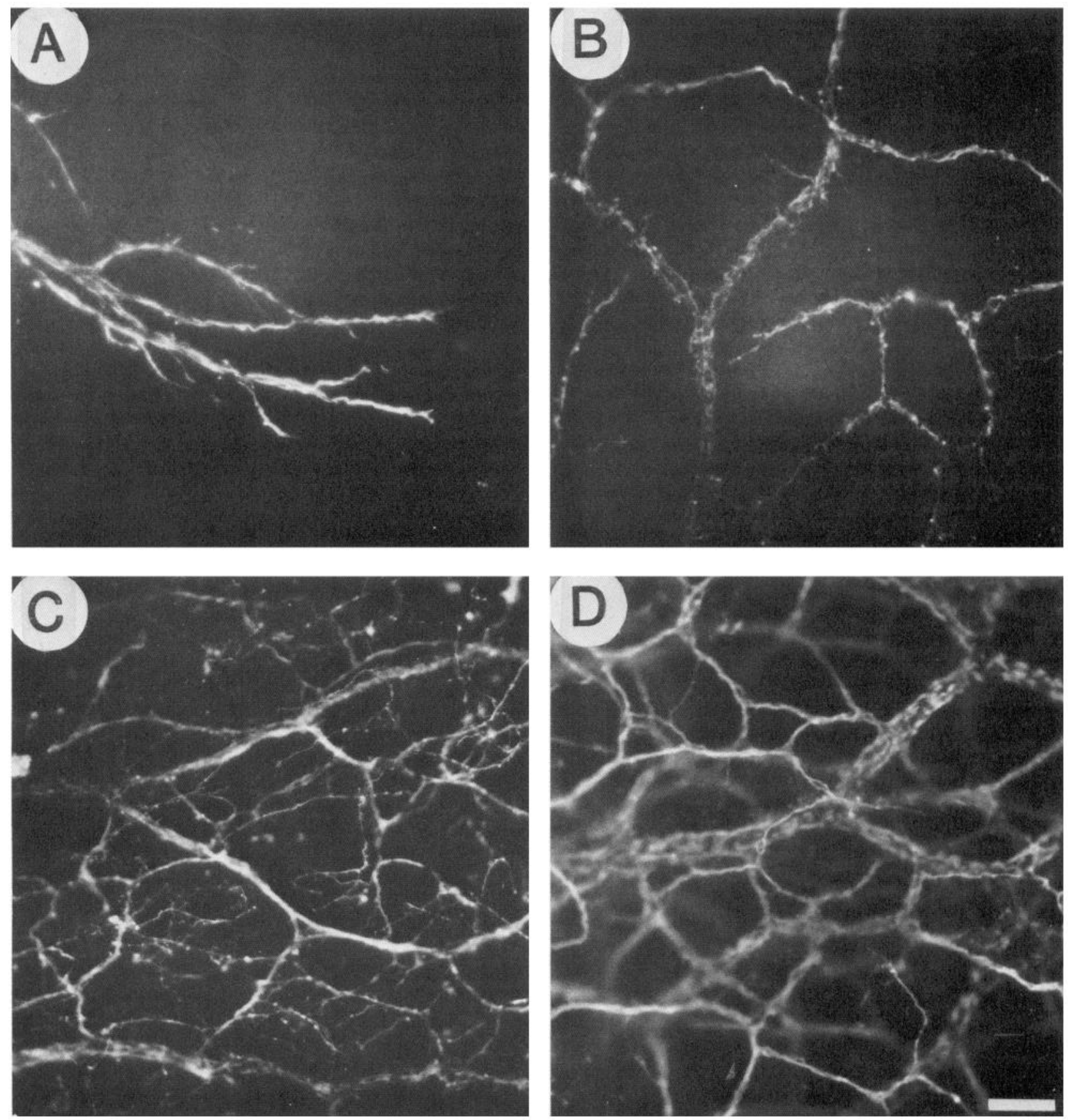

Figure 14. Developmental appearance of choroid nerves (observed by immunostaining) in the choroid coat. $A$, At St 29, choroid nerves are spreading over the peripheral tissue. B. By St 33, the nerves begin to ramify and traverse most of the peripheral area. $C$, By St 38 , a network of fibers begins to innervate the choroid. $D$. At St 43, an increased density of innervation is observed. All micrographs are from the same identified region of the choroid (see Materials and Methods).

cation or nerve stimulation with a contraction sufficient to move blood in the choroidal vessels, RBC movement was observed at various developmental time periods (see Table 1). Thirtyhertz stimulation of the choroid nerve was required to move blood cells in choroidal vessels, but it could do so only after St 44. This is not surprising, since embryonic nerve terminals would be expected to fatigue with repetitive stimulation (see Fig. 11). $\mathrm{ACh}$ application, however, was able to induce $\mathrm{RBC}$ movement as early as St 36 . Both nerve- and ACh-induced blood flow was blocked by atropine, indicating that the response is muscarinic and begins at about the same time as does the TEA-prostigmineenhanced electrical activity in the choroid coat. It is possible, however, that the $\mathrm{ACh}$-induced blood flow at early embryonic ages is primarily due to activation of the more differentiated, and most likely uninnervated, inner layer of arteriole smooth muscle. Therefore, although this indicates that AChRs are present, we cannot determine whether this activation is relevant to cholinergic innervation, since we have not observed innervation of these early-differentiating arteriole smooth muscle cells. Nevertheless, we can conclude that functional AChRs appear 


\begin{tabular}{llll}
\hline $\begin{array}{l}\text { Table 1. Observations of blood flow following nerve or ACh } \\
\text { stimulation }\end{array}$ & \multicolumn{3}{l}{. } \\
Embryonic & $\begin{array}{l}\text { Embryonic } \\
\text { stage }\end{array}$ & Response to \\
\cline { 2 - 4 } day & 34 & - & $30 \mathrm{~Hz}$ \\
\hline 8 & 36 & + & - \\
10 & 38 & + & - \\
12 & 40 & + & - \\
14 & 42 & ++ & - \\
16 & 44 & +++ & + \\
18 & & +++ & +++ \\
3 dph & &
\end{tabular}

If blood flowed in most of the vessels observed, +++ was scored. If about half responded, ++ was scored, and if only several responded, + was scored. When no blood flow was observed following chemical or electrical stimulation. - was scored.

on contractile muscle by $\mathrm{St} 36$. It is also possible that AChRs are present on precursors of smooth muscle cells that we cannot detect with our method.

\section{Discussion}

The vascular choroid coat lining the back of the eye has been described in the monkey and rabbit (Ruskell, 1961, 1970; Bill, 1962), but the cholinergic innervation of this structure in mammals is not well understood. In mammals, the source of parasympathetic innervation arises from the sphenopalatine ganglion and mediates vasodilation (Ruskell, 1971). Adrenergic nerves also innervate choroid blood vessels, and sympathetic activation results in vasoconstriction (Bill, 1962). In the present work, we describe the parasympathetic cholinergic inncrvation of the choroid in the chicken by the ciliary ganglion. We have shown that the choroid cholinergic motoneurons of the ganglion project into the choroid coat and ramify by about St 33 , but they do not initiate muscular activity in the smooth muscles until St 36. In vitro, measurement of this early muscular activation requires the presence of the anticholinesterase (prostigmine). In addition, we have shown that choroid neuromuscular synapses are entirely muscarinic from embryonic stages to hatching.

The regulation of blood flow in the choroid is particularly important in birds, since there is no central artery of the retina. The functions of this innervation in birds revolve around alterations in blood flow in this heavily vascularized tissue. When the postganglionic choroid nerves leaving the ciliary ganglion are repetitively stimulated, RBCs move in the vessels of the choroid. It is possible that this regulation of blood flow involves a parasympathetic retinal reflex pathway, described by Reiner et al. (1983). Since the choroid may provide the major blood supply to the outer layers of the retina, metabolic demands resulting from retinal illumination may be met by increased blood flow through the choriocapillaris. The choriocapillaris may also be involved in the regulation of ionic transport across the pigment epithelium. It is of interest that an increase in blood flow within the mammalian eye has been demonstrated following an increase in retinal illumination (Parver et al., 1982). The choroid may also play a role by preventing damage of the retina by increasing blood flow during changes in ambient light levels. Photoreceptors in the retina have been shown to degenerate following blockage of choroidal blood flow (Gay et al., 1964; Golder and Gay, 1967) or sustained exposure to slightly higher than normal levels of illumination (Lanum, 1978). Furthermore, intraocular pressure would be very sensitive to changes in choroidal blood flow. It is possible that the lacunae serve as a liquid reservoir and regulate intraocular pressure by filtering fluid out of the blood vessels. The choroid coat innervation previously described may be important in regulating intraocular pressure. Glaucoma, one of the leading causes of blindness in mammals, occurs when intraocular pressure is high enough to cause damage to ncrve fibers in the retina. This disorder is normally treated with anticholinesterases, which presumably produce vasodilation and decrease intraocular pressure. An understanding of the regulation of intraocular pressure and its control by the innervation described in this work may be useful as a model for studies of intraocular pressure changes in mammals.

The characterization of the innervation of the choroid may be critical to the processes described above, but it is also important embryologically, since the number of cholinergic motoneurons innervating the choroid is reduced by about $50 \%$ during a critical time in development. Neuromuscular interactions between motoneurons and skeletal muscle have been studied extensively; however, these observations have not previously been extended to the motor innervation of smooth muscle. The ciliary ganglion-choroid smooth muscle system is well suited to these studies because of the compact and peripheral location of the motoneurons and the accessibility of the choroid smooth muscle. These data are essential to the experimental study described in the following paper (Meriney et al., 1987), on the normal neuronal death among the choroid motoneurons. It is interesting that, as in other tissues, choroid motor nerve processes are present in the target environment before the onset of the normal neuronal death. However, unlike the well-studied skclctal ncuromuscular junction, they do not make functional synaptic contacts until St 36 (at least $1 \mathrm{~d}$ after the onset of the cell death). This implies that competitive interactions between choroid motoneurons and choroidal targets may exist before functionally effective transmission begins, an idea discussed more fully in the subsequent paper (Meriney et al., 1987).

\section{References}

Armstrong, C. M. (1966) Time course of TEA-induced anomalous rectification in squid giant axon. J. Gen. Physiol. 50: 491-503.

Axelsson, J. (1970) Mechanical properties of smooth muscle, and the relationship between mechanical and electrical activity. In Smooth Muscle, E. Bulbring, A. F. Brading, A. W. Jones, and T. Tomita, eds., pp. 298-314, Williams \& Wilkins, Baltimore, MD.

Bill, A. (1962) Autonomic nervous control of uveal blood flow. Acta Physiol. Scand. 56: 70-81.

Droogmans, G., L. Raeymaekers, and R. Casteels (1977) Electro- and pharmacomechanical coupling in the smooth muscle cells of the rabbit ear artery. J. Gen. Physiol. 70: 129-148.

Gay, A. J., H. Golder, and M. Smith (1964) Chorioretinal vascular occlusions with latex spheres. Invest. Ophthalmol. 3: 647-656.

Golder, H., and A. J. Gay (1967) Chorioretinal vascular occlusions with latex microspheres (a long term study). Part II. Invest. Ophthalmol. 6: 51-58.

Hamburger, V., and H. L. Hamilton (1951) A series of normal stages in the development of the chick embryo. I. Morphol. 88: 49-92.

Holman, M. E., and T. O. Neild (1979) Smooth muscle: Membrane properties. Br. Med. Bull. 35: 235-241.

Kirby, M. L., I. M. Diab, and T. G. Mattio (1978) Development of adrenergic innervation of the iris and fluorescent ganglion cells in the choroid of the chick eye. Anat. Rec. 191: 311-320.

Landmesser, L., and G. Pilar (1974) Synaptic transmission and cell death during normal ganglionic development. J. Physiol. (Lond.) 241 . 737-749.

Lanum, J. (1978) The damaging effects of light on the retina. Empirical 
findings, theoretical and practical implications. Surv. Ophthalmol. 22: 221-248.

Lasansky, A., and F. W. de Fisch (1966) Potential, current, and ionic fluxes across the isolated retinal pigment epithelium and choroid. J. Gen. Physiol. 49: 913-924.

Letinsky, M. S. (1974) Physiological properties of developing frog tadpole nerve-muscle junctions during repetitive stimulation. Dev. Biol. 40: 154-161.

Marwitt, R., G. Pilar, and J. N. Weakly (1971) Characterization of two cell populations in the avian ciliary ganglion. Brain Res. $25: 317-$ 334.

Meriney, S. D., G. Pilar, M. Ogawa, and R. Nuñez (1987) Differential neuronal survival in the avian ciliary ganglion after chronic acetylcholine receptor blockade. J. Neurosci. 7: 3840-3849.

Merrillees, N. C. R. (1968) The nervous environment of individual smooth muscle cells of the guinea pig vas deferens. J. Cell Biol. 37: 794-817.

Noell, W. K., D. Crapper, and C. V. Paganelli (1965) Transretinal currents and ion fluxes. In Transcellular Membrane Potentials and Ion Fluxes, F. M. Snell and W. K. Noell, eds., p. 92, Gordon and Breach, New York.

Parver, L. M., C. Auker, D. O. Carpenter, and T. Doyle (1982) Choroidal blood flow. II. Reflexive control in the monkey. Arch. Ophthalmol. 100: 1327-1330.
Pilar, G., L. Landmesser, and L. Burstein (1980) Competition for survival among developing ciliary ganglion cells. J. Neurophysiol. 43: 233-254.

Pilar, G., J. Tuttle, and K. Vaca (1981) Functional maturation of motor nerve terminals in the avian iris: Ultrastructure, transmitter metabolism and synaptic reliability. J. Physiol. (Lond.) 321: 175-193.

Reiner, A., H. J. Karten, P. D. R. Gamlin, and J. T. Erichsen (1983) Parasympathetic ocular control. Trends Neurosci. 6: 1-6.

Rochon-Duvigneaud, A. (1943) Les yeux et la vision des vertebres, p. 452, Masson, Paris.

Ruskell, G. L. (1961) Aqueous drainage paths in the rabbit. Arch. Opthalmol. 66: 861-864.

Ruskell, G. L. (1970) An ocular parasympathetic nerve pathway of facial nerve origin and its influence on intraocular pressure. Exp. Eye Res. 10: 319-330.

Ruskell, G. L. (1971) Facial parasympathetic innervation of the choroidal blood-vessels in monkeys. Exp. Eye Res. 12: 166-172.

Tachibana, S., M. Takeuchi, and T. Fugiwara (1985) Visualization of autonomic varicose terminal axons by scanning electron microscopy. J. Electron Microsc. 34: 136-138.

Yamamoto, M., A. M. Boyer, J. E. Crandall, M. Edwards, and H. Tanaka (1986) Distribution of stage-specific neurite-associated proteins in the developing murine nervous system recognized by a monoclonal antibody. J. Neurosci. 6: 3576-3594. 